\title{
Role of Perioperative Echocardiography in Revision of Assessment: A Condition of Severe Aortic Stenosis leading to Left Ventricular Dysfunction and Apical Clot
}

\author{
${ }^{1}$ Imran H Bhat, ${ }^{2}$ Banashree Mandal, ${ }^{3}$ Srinath Damodaran, ${ }^{4}$ Rupesh Kumar
}

\begin{abstract}
The prevalence of discrete subaortic stenosis (SAS) in adults with congenital heart disease (CHD) is 8 to $20 \%$, with a male to female ratio of $2: 1$. Fixed SAS may be due to a discrete fibrous membrane, a muscular narrowing, or a combination of the two. The discrete form of fibromuscular SAS is most frequently encountered (90\%), but the tunnel-type lesions are associated with a greater degree of stenosis. We report the case of a 16 -year-old boy scheduled for double valve replacement (DVR) based on the preoperative echocardiographic report of rheumatic heart disease (RHD) with severe aortic stenosis (AS), severe aortic regurgitation (AR) and moderate mitral stenosis (MS), and moderate mitral regurgitation (MR) with severe left ventricular (LV) systolic dysfunction and LV apical clot. Preoperative transthoracic echocardiography (TTE) in the operation theater revealed discrete subaortic membrane (SAM) causing severe LV outflow tract obstruction (LVOTO). The patient underwent open heart surgery with resection of the discrete membrane and removal of apical clot.
\end{abstract}

Keywords: Cardiomyopathy dilated, Congenital, Discrete subaortic stenosis, Echocardiography, Heart auscultation, Heart defects, Perioperative.

How to cite this article: Bhat IH, Mandal B, Damodaran S, Kumar R. Role of Perioperative Echocardiography in Revision of Assessment: A Condition of Severe Aortic Stenosis leading to Left Ventricular Dysfunction and Apical Clot. J Perioper Echocardiogr 2017;5(2):77-81.

Source of support: Nil

Conflict of interest: None

\section{INTRODUCTION}

Fixed subaortic stenosis accounts for 8 to $20 \%$ of patients with congenital LVOTO. Three anatomical variants have been described: (i) Collar type, in which a fibromuscular

\footnotetext{
1,3 Senior Resident, ${ }^{2}$ Associate Professor, ${ }^{4}$ Assistant Professor

1-3 Department of Anesthesia and Intensive Care, Postgraduate Institute of Medical Education and Research, Chandigarh, India

${ }^{4}$ Department of Cardiothoracic and Vascular Surgery, Postgraduate Institute of Medical Education and Research, Chandigarh, India

Corresponding Author: Banashree Mandal, Associate Professor Department of Anesthesia and Intensive Care, Postgraduate Institute of Medical Education and Research, Chandigarh, India Phone: +917087008016, e-mail: banashreemandal@yahoo.co.in
}

ridge is present; (ii) diffuse long segment fibromuscular narrowing or tunnel type; and (iii) discrete membranous SAS or SAM, which is characterized by a crescent-shaped or complete circular thickening of the endocardium on the ventricular septum in the form of a thin fibrous membrane, just caudal to the aortic valve cusps and on a plane usually corresponding to the level of the annulus fibrosus of the mitral valve. Subaortic membrane is the most common of the obstructions. ${ }^{1}$ It is usually associated with other congenital anomalies in 60 to $70 \%$ of cases, e.g., ventricular septal defects (VSD), bicuspid AV, coarctation of aorta, and atrioventricular septal defect (AVSD). The LVOTO is almost always progressive but at a variable rate. Subaortic stenosis is rarely diagnosed antenatally or in infancy but often manifests in the first decade of life with features of progressive LVOTO, LV hypertrophy and LV dysfunction, or AR. The post stenotic jet from the narrowed subaortic tract damages the aortic cusps and causes regurgitation; this damage may also render the aortic valve prone to infective endocarditis. ${ }^{2}$ Treatment options are balloon dilatation or surgical excision of the obstruction. ${ }^{3}$

\section{CASE REPORT}

A 16-year-old boy was scheduled for DVR based on the preoperative TTE report of RHD with severe AS, and $\mathrm{AR}$, moderate $\mathrm{MS}$ and mitral regurgitation with severe LV dysfunction and LV apical clot. On physical examination, the patient's heart rate was found to be $98 \mathrm{bpm}$, regular, and good volume, with bisferiens and water hammer character was felt equally in all limbs. Cardiovascular examination revealed a diastolic murmur at right parasternal aortic area and systolic ejection murmur at neoaortic area. Preoperative TTE in operation theatre revealed discrete SAM causing severe LVOTO (peak systolic velocity $>4 \mathrm{~m} / \mathrm{s}$; Fig. 1) associated with AR (Fig. 2; Videos $1 \mathrm{~A}$ and $\mathrm{B}$ ) and trivial MR and dilated LV [LV end diastolic diameter (LVEDD) $=61 \mathrm{~mm}$ ] (Fig. 3) with severe $\mathrm{LV}$ systolic dysfunction [LV ejection fraction $(\mathrm{LVEF})=$ $30 \%$ ] (Videos 2A and B) and presence of LV apical mass (measuring $1.5 \times 2.5 \mathrm{~cm}$; Fig. 4; Video 3). The aortic valve was morphologically normal and the mechanism for AR 


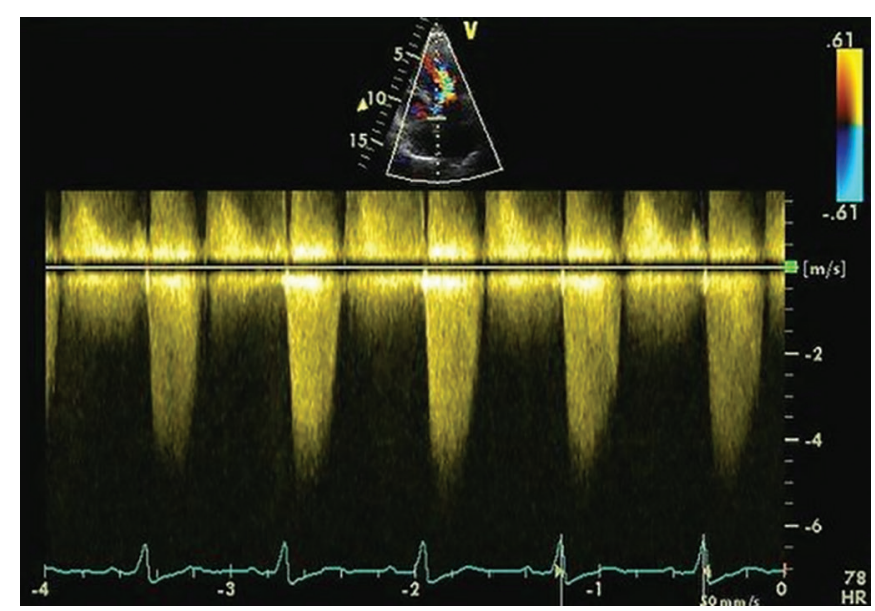

Fig. 1: Transthoracic echocardiography: Apical five-chamber view showing severe LVOTO (peak systolic velocity $>4 \mathrm{~m} / \mathrm{s}$ )

was assumed to be occurring because of the poststenotic LVOT jet impinging on the aortic valve leaflets, particularly on right coronary cusp (RCC) causing coaptation defect because of coanda effect (suctioning effect on RCC causing it to prolapse into LVOT) (Fig. 5) that was clearly appreciated in aortic valve short-axis imaging on both TTE and transesophageal echocardiography (TEE). The mitral valve was funnel-shaped with chordal insertion on two separate heads of single papillary muscle (Fig. 6) resulting in trivial MR with no stenosis. All these findings were confirmed on TEE. Thus, the surgical plan was changed to resection of SAM and removal of LV apical clot only. Postsurgical TEE detected only mild AR (Video 4) not warranting any intervention. Patient did well in the immediate postoperative period, and during follow-up had an improved LV systolic function.

\section{DISCUSSION}

Perioperative echocardiography has become a critical diagnostic and management tool for patients with CHD undergoing cardiac surgical procedures. This report emphasizes the role of perioperative TTE and
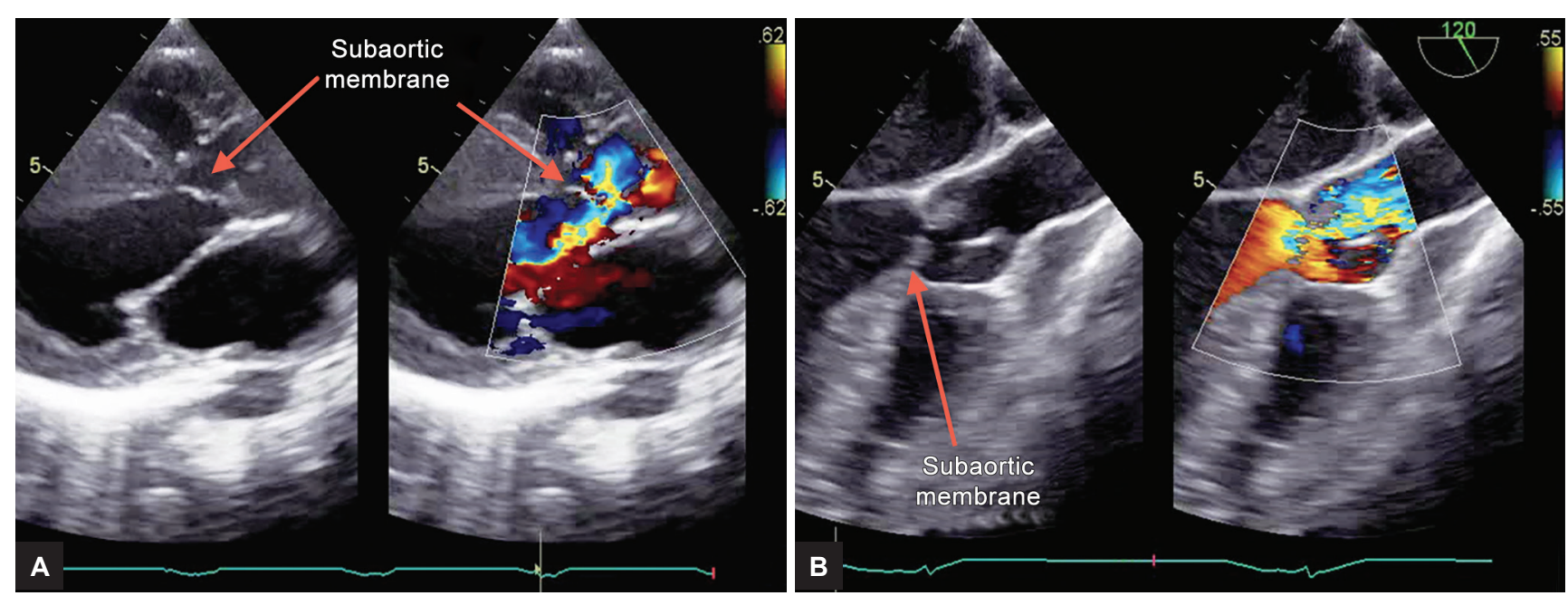

Figs 2A and B: (A) Transthoracic echocardiography: Parasternal long-axis view discrete subaortic membrane resulting in AS and $A R$; and (B) TEE: Midesophageal long-axis view showing discrete subaortic membrane leading to systolic flow turbulence
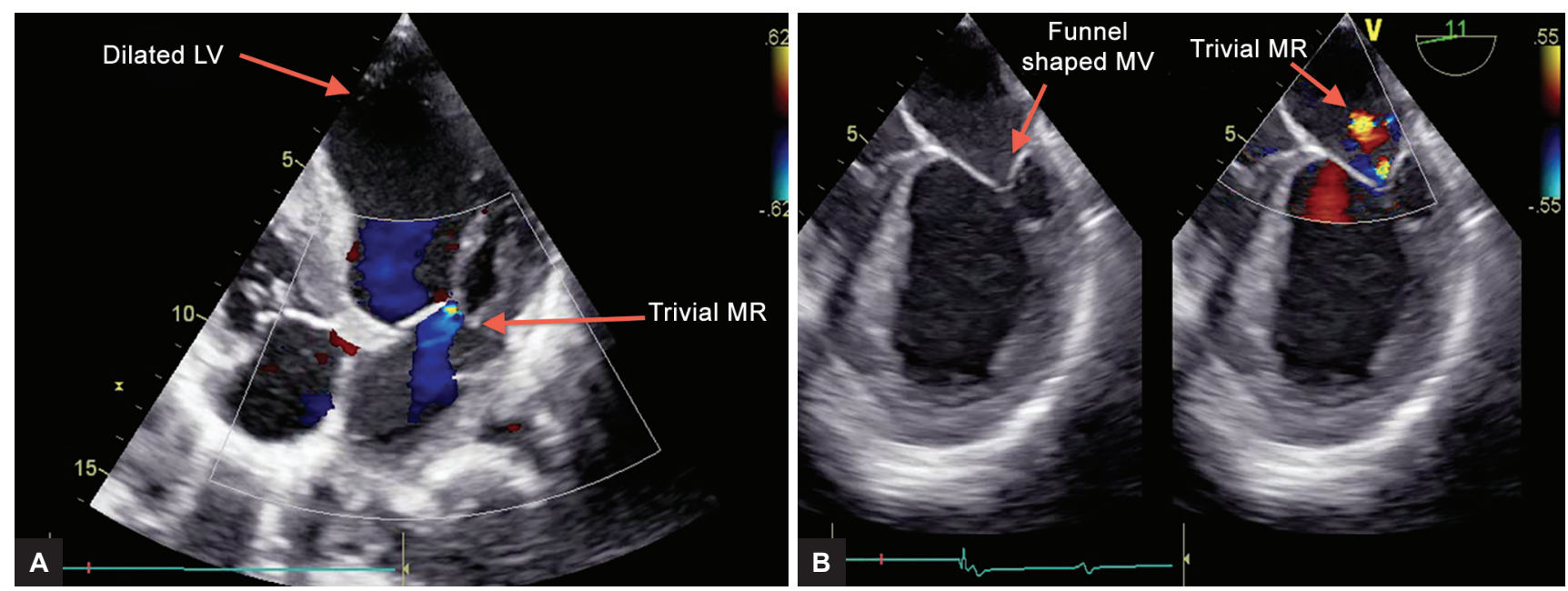

Figs 3A and B: (A) Transthoracic echocardiography: Apical four-chamber view dilated LV and trivial MR; (B) TEE: Trivial MR was noticed across the funnel-shaped MV in the midesophageal four-chamber view 

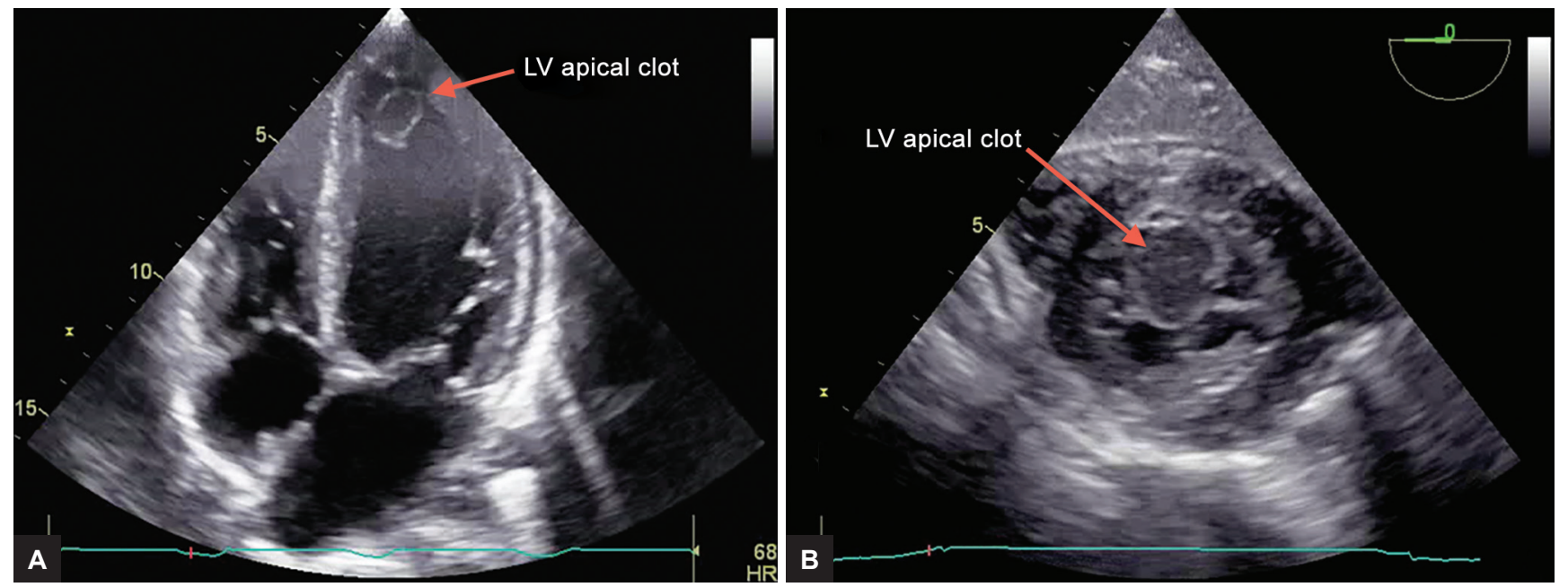

Figs 4A and B: (A) Transthoracic echocardiography: Apical four-chamber view showing dilated LA/LV with apical mass (clot); and (B) TEE: LV apical mass (clot) as seen in transgastric apical short-axis view
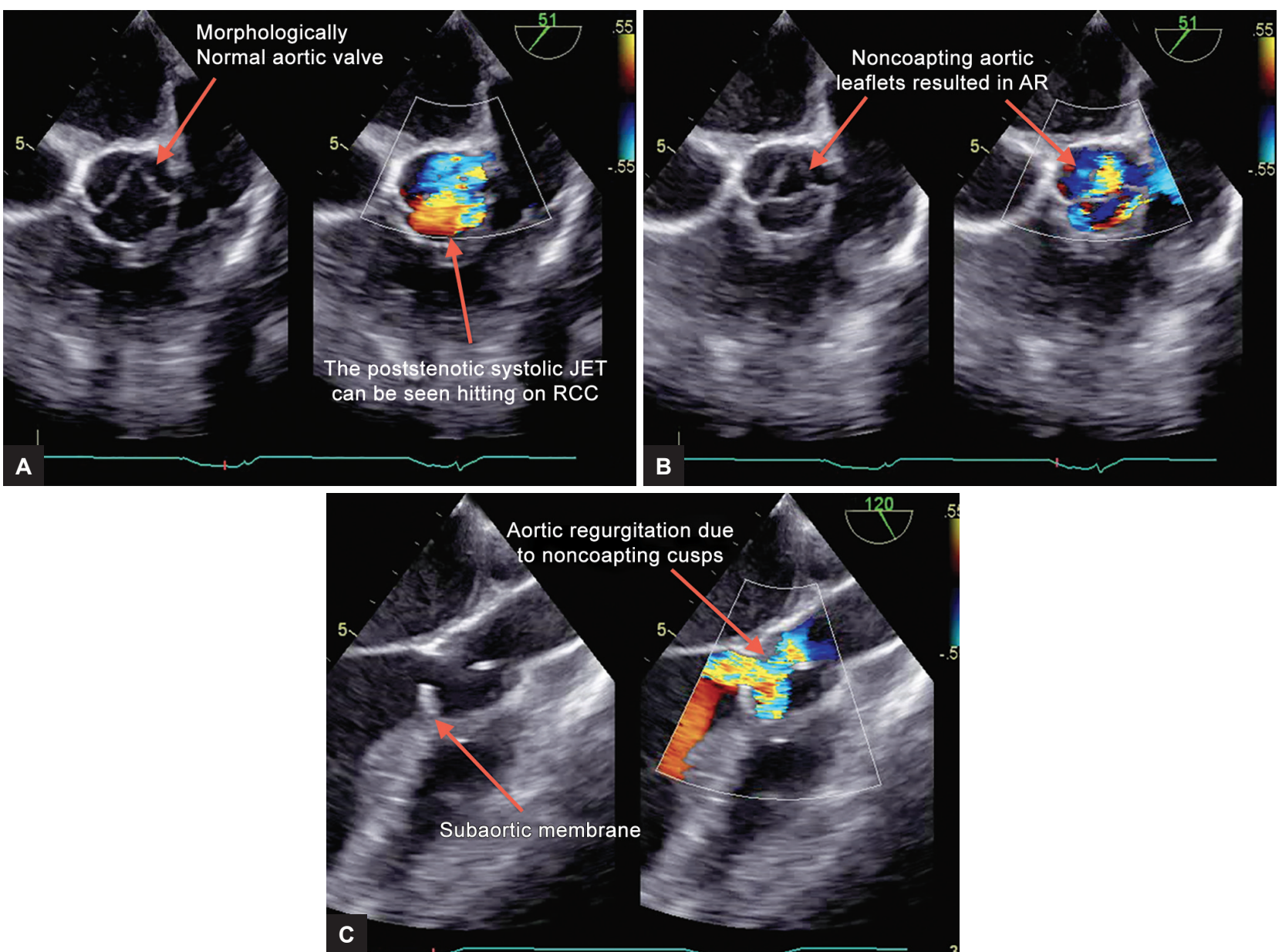

Figs 5A to C: (A) Transthoracic echocardiography: Poststenotic systolic jet can be seen hitting on the RCC of the morphologically normal trileaflet aortic valve in midesophageal aortic valve short-axis view; (B) TEE: Diastolic run off can be seen, in the midesophageal aortic valve short-axis view, occurring via the noncoapting aortic leaflets resulting in AR; and (C) TEE: Severe AR resulting from noncoaption of leaflets can be appreciated in midesophageal AV long-axis view

TEE in routine management of pediatric cardiac patient population. Transesophageal echocardiography has proven to be invaluable in confirming preoperative diagnosis, formulating surgical plan, evaluating immediate operative result, identifying residual defect, and guiding surgical revision. Intraoperative use is currently the most common indication of TEE in the pediatric age group. Numerous reports since the technology became available have documented the benefits of this approach, and the experience to date accounts for the incorporation of TEE 


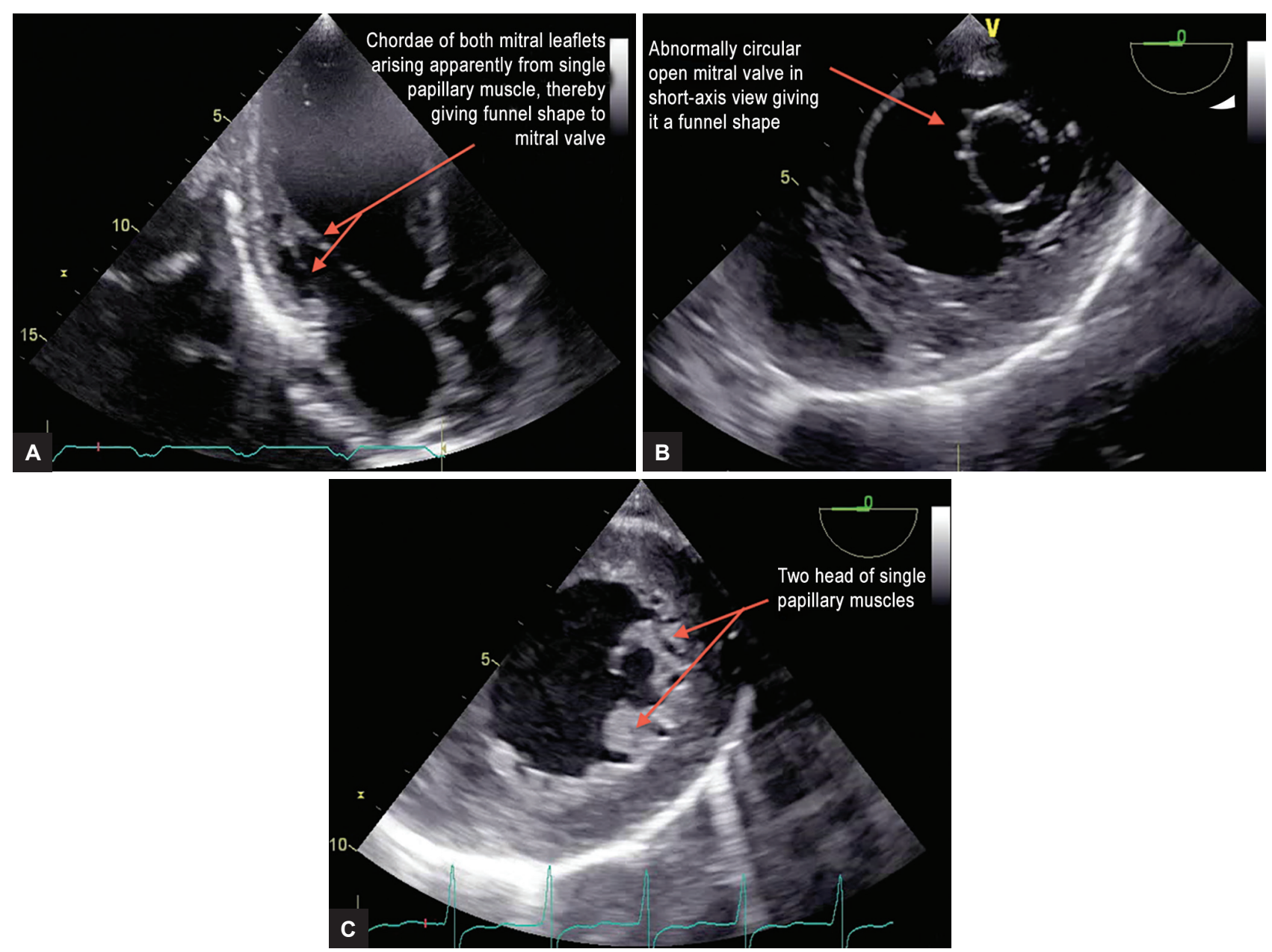

Figs 6A to C: (A) Transthoracic echocardiography: Apparently, the chordae of both leaflets of MV seemed to take origin from single papillary muscle, as seen in apical three-chamber view; (B) TEE: Transgastric basal short-axis view showing abnormally circular shape of mitral valve opening during diastole; and (C) TEE: Transgastric midpapillary short-axis view showing two heads of single papillary muscle, resulting in abnormal funnel shape of mitral valve

into the standard of care of patients undergoing surgery for CHD at many centers worldwide. Transesophageal echocardiography can corroborate preoperative diagnoses and define the anatomical abnormalities prior to the surgical intervention. In case of unsatisfactory transthoracic images or incomplete diagnostic data, TEE can help acquire the relevant missing information. In a previous study at our institution, baseline TTE in the operating room showed new findings leading to change in surgical plan in $3.1 \%$ of patients, while additional new findings were seen in $2.6 \%$ of patients. ${ }^{4}$ Jijeh et $\mathrm{al}^{5}$ identified variations between TEE and preoperative TTE in 14 patients $(1.3 \%)$. Another series observed high preoperative impact of TEE on the diagnosis up to $9.1 \% .{ }^{6}$ The main benefit of a preoperative TEE study is that it allows the surgeon to review anatomy and findings immediately before surgery. ${ }^{7}$ Subaortic stenosis results from anatomic alteration in the LVOT. Significant pressure gradient and AR are the main indications for surgery; controversy persists about the timing of surgical repair and the surgical technique. ${ }^{8}$ Surgery has been suggested for patients in whom LV-aorta gradients exceed $30 \mathrm{~mm} \mathrm{Hg}$ or a coexisting cardiac defect that requires surgical correction, while others advocate surgical resection for SAM of any degree because of concerns about the developmental role that SAS may play in aortic insufficiency, LV hypertrophy, and infective endocarditis. Moreover, surgical resection of fixed SAS before the development of a significant outflow tract gradient $(>40 \mathrm{~mm} \mathrm{Hg}$ ) may prevent recurrence and reoperation. ${ }^{9}$ The optimal surgical method for patients with SAM is debatable. Some surgeons prefer enucleation of the discrete membrane and in selected patients its fibromuscular ridge, many others believe that surgery is not sufficient without routine myectomy along with resection of the hypertrophied muscle. Radical excision of all diseased tissue, which attains a minimal early postoperative gradient, may reduce the occurrence of late AR. ${ }^{10}$ However, the more aggressive approach increases the risk of iatrogenic damage to the conduction tissue (injury to the conduction tissue between the right and noncoronary cusps), VSD, and mitral valve. Regrowth from the initial site of fibromuscular obstruction over 
septum may be an important cause of recurrence; therefore, removal of the underlying septal muscle may prevent the recurrence. ${ }^{11}$ The other cause of recurrence may be that scar formation from the original excision fixes the diameter of the LVOT and limits its growth. The patient had dilated left ventricular (LVEDD $>60 \mathrm{~mm}$ ) and $\mathrm{LVEF}<35 \%$, thereby increasing the chances of $\mathrm{LV}$ thrombus formation. ${ }^{12}$ Mild degree of MR could be because of the dilated LV.

\section{CONCLUSION}

Perioperative echocardiography is a critical diagnostic tool for patients with CHD undergoing cardiac surgical procedures. An observant perioperative TTE and TEE examination can guide the surgeon to revise the decision in the operating room.

\section{REFERENCES}

1. Newfeld EA, Muster AJ, Paul MH, Idriss FS, Riker WL. Discrete subvalvularaortic stenosis in childhood. Am J Cardiol 1976 Jul;38(1):53-61.

2. Kleinert S, Ott DA, Geva T. Critical discrete subaortic stenosis in the newborn period. Am Heart J 1993 Apr;125(4):1187-1189.

3. Shrivastava S, Dev V, Bahl VK, Saxena A. Echocardiographic determinants of outcome after percutaneous transluminal balloon dilatation of discrete subaortic stenosis. Am Heart J 1991 Nov;122(5):1323-1326.

4. Mishra A, Madhavan JS, Ghuman BPS, Raj R, Kumar A, Dutta V, Negi S, Tandon Y, Kumar A, Arya VK, et al. Impact and cost effectiveness of routine intraoperative transthoracic and transesophageal echocardiography on surgical decision making in pediatric cardiac surgery. J Perioper Echocardiogr 2014 Jan-Jun;2(1):3-9.

5. Jijeh AM, Omran AS, Najm HK, Abu-Sulaiman RM. Role of intraoperative transesophageal echocardiography in pediatric cardiac surgery. J Saudi Heart Assoc 2016 Apr;28(2): 89-94.

6. Eltzschig HK, Rosenberger P, Löffler M, Fox JA, Aranki SF, Shernan SK. Impact of intraoperative transesophageal echocardiography on surgical decisions in 12,566 patients undergoing cardiac surgery. Ann Thorac Surg 2008 Mar;85(3): 845-852.

7. Sheil ML, Baines DB. Intraoperative transoesophageal echocardiography for paediatric cardiac surgery-an audit of 200 cases. Anaesth Intensive Care 1999 Dec;27(6):591-595.

8. Rayburn ST, Netherland DE, Heath BJ. Discrete membranous subaortic stenosis: improved results after resection and myectomy. Ann Thorac Surg 1997 Jul;64(1):105-109.

9. Parry AJ, Kovalchin JP, Suda K, McElhinney DB, Wudel J, Silverman NH, Reddy VM, Hanley FL. Resection of subaortic stenosis; can a more aggressive approach be justified? Eur J Cardiothorac Surg 1999 May;15(5):631-638.

10. Lupinetti FM, Pridjian AK, Callow RN, Crowley DC, Beekman RH, Bove EL. Optimum treatment of discrete subaortic stenosis. Ann Thorac Surg 1992 Sep;54(3): 467-471.

11. Brauner R, Laks H, Drinkwater DC Jr, Shvarts O, Eghbali K, Galindo A. Benefits of early surgical repair in fixed subaortic stenosis. J Am Coll Cardiol 1997 Dec;30(7):1835-1842.

12. Erbay AR, Turhan H, Senen K, Yetkin F, Ayaz S, Kara F, Buyukasik NS, Yetkin E. Predictors of left ventricular thrombus formation in patients with dilated cardiomyopathy: role of activated protein C resistance. Coron Artery Dis 2004 Mar;15(2):107-110. 